\title{
Analisis Kemampuan Pedagogical Content Knowledge (PCK) Calon Guru MI Pada Konsep IPA Dalam Menghadapi Pendidikan Abad 21
}

\author{
Suci Nurmatin a, 1*, Dudung Abdurrahman ${ }^{\text {b2 }}$ \\ ${ }^{a}$ STAI Tasikmalaya, Tasikmalaya \\ ${ }^{\mathrm{b}}$ Universitas Garut, alamat, kota dan kode pos \\ ${ }^{1}$ suci.nurmatin@gmail.com* \\ *korespondensi penulis
}

\begin{abstract}
ABSTRAK
Penelitian ini bertujuan untuk menganalisis kemampuan Pedagogical Content Knowledge (PCK) guru MI pada konsep IPA dalam rangka menghadapi pendidikan abad 21. Enam orang orang mahasiswa yang mengikuti mata kuliah Pendidikan IPA dijadikan sebagai partisipan. Data kemampuan PCK subjek diperoleh berdasarkan hasil observasi saat partisipan melaksanakan simulasi pembelajaran. Hasil analisis kemampuan PCK partisipan saat simulasi pembelajaran menunjukkan bahwa kemampuan pedagogi dan konten secara terpisah sudah cukup baik, namun integrasi antara kemampuan pedagogi dengan kemampuan kontent belum terlihat baik. Dengan demikian kemampuan PCK partisipan dalam menghadapi pendidikan abad 21 belum maksimal.
\end{abstract}

Kata kunci : PCK, Konsep IPA, Pendidikan Abad 21

ABSTRACT

This study aims to analyze Pedagogical Content Knowledge (PCK) ability of prospective primary teacher in concept IPA in facing $21^{\text {st }}$ Century Education. Six college student who took the Science Education course made as participant. Data on PCK ability is obtained based on the result of observation when participants carry out learning simulation. The results of the analysis of the participants' PCK abilities during the learning simulation showed that their pedagogical skills and content separately were good enough, but the integration between pedagogical skills and abilities was not yet good. Thus the ability of PCK participants in facing 21 st century education has not been maximal.

Keyword: PCK, Concept IPA, $21^{\text {st }}$ Century Education

\section{PENDAHULUAN}

Pendidikan dasar memiliki pengaruh yang besar terhadap perkembangan kemampuan kognitif, motorik dan afektif peserta didik. Dengan demikian, pendidikan dasar pada tingkat Madrasah Ibtidaiyah (MI) memerlukan persiapan yang baik, mulai dari mempersiapkan konten sampai pada metode menyampaikan konten kepada peserta didik. Konten materi untuk tingkat MI merupakan konten yang menggabungkan antar materi pelajaran untuk sebuah tema tertentu yang dinamakan pembelajaran tematik. Tematik pada tingkat dasar merupakan gabungan dari empat materi ajar yakni Bahasa Indonesia, Seni Budaya dan Kesenian (SBK), Pendidikan Kewarganegaraan (PKN), Ilmu Pengetahuan Sosial (IPS) dan Ilmu Pengetahuan Alam (IPA). Khusus untuk penelitian ini akan difokuskan pada materi ajar IPA saja. Materi ajar IPA yang terintegrasi dengan materi ajar lain dalam suatu tema harus diolah guru dengan baik, agar konsep IPA dapat diterima oleh peserta didik. Kemampuan guru dalam mengajar yang baik diperlukan agar hal ini dapat tercapai.

Dalam Peraturan Menteri Pendidikan Nasional tentang Standar Kualifikasi dan Kompetensi Guru menyatakan bahwa seorang guru seharusnya memiliki empat kompetensi. Empat kompetensi yang diungkapkan dalam Peraturan Menteri No 16 Tahun 2007 adalah kompetensi pedagogi, kompetensi kepibadian, kompetensi sosial dan kompetensi professional. Dua kompetensi yang terdapat dalam Peraturan Menteri No 16 Tahun 2007 yakni kompetensi pedagogi dan kompetensi profesional, sesuai dengan kemampuan guru yang diungkapkan oleh Shulman yakni Pedagogical Content Knowledge (PCK). PCK pertama kali dikenalkan Shulman (1987) sebagai komponen inti dalam mengajar yang 
menekankan bahwa pengajaran tidak sekedar pengetahuan tentang materi pelajaran namun, pengajaran yang efektif adalah pengajaran yang menggabungkan antara pengetahuan konten dengan pengetahuan pedagogik (Brown et al, 2013; Kaya, 2009; Hanuscin, 2013). PCK menjadi fokus seorang guru dalam menyelidiki profil dan peningkatan kemampuan guru IPA (Rustaman \& Widodo, 2013). Dengan demikian, agar konsep IPA dapat diterima dengan mudah oleh peserta didik maka guru harus memiliki kemampuan yang dapat mengintegrasikan antara kemampuan dalam konsep IPA dengan kemampuan pedagoginya. Sementara, saat ini sebagian besar pelaku pendidikan menganggap bahwa pengetahuan konsep IPA lebih penting dimiliki oleh seorang guru. Hal tersebut mengakibatkan adanya ketidaksesuaian antara cara penyampaian guru dengan keinginan siswa dalam menerima sebuah konsep IPA.

Konsep IPA sering dijadikan sebagai konsep yang rumit sehigga tidak sedikit peserta didik yang tidak senang dengan konsep IPA. Peminat konsep IPA yang rendah seharusnya dijadikan sebagai dorongan bagi guru untuk meningkatkan kemampuannya dalam mengajar konsep IPA terutama dalam menghadapi pendidikan abad 21. Pendidikan abad 21 merupakan pendidikan yang menekankan pada kemampuan siswa untuk berpikir kritis, mampu menghubungkan ilmu dengan dunia nyata, menguasai teknologi informasi komunikasi, dan berkolaborasi (Janah dkk, 2019). Kriteria pendidikan abad 21 yang diungkapkan oleh Jannah dkk (2019) sesuai dengan pilar pendidikan yang diungkapkan oleh UNESCO yakni learning to know, learning to do, dan learning to live together. Penerapan tiga pilar yang diungkapkan oleh UNESCO dalam pembelajaran disesuaikan dengan karakteristik peserta didik saat ini. Karakteristik peserta didik tingkat dasar di era pendidikan abad 21 dikenal dengan generasi Z. Siswa generasi $\mathrm{Z}$ memiliki kemampuan yang berbeda dengan generasi-generasi sebelumnya karena mereka lahir pada era digitalisasi. Dengan karakteristik generasi $Z$ yang dekat dengan dunia digitalisasi maka terdapat dua solusi untuk mengembangkan kemampuan mereka sesuai dengan kemampuan yang diinginkan pendidikan abad 21 (Mubarak, 2018). Pertama, memadukan pendidikan tradisional dengan pendidikan digital. Kedua, pendidikan dengan menggunakan digital secara keseluruhan. Kedua solusi menghadapi pendidikan abad 21 perlu didukung oleh kemampuan PCK guru dalam dunia digital.

Kemampuan PCK secara lengkap dapat diperoleh ketika proses mengajar di kelas, namun meskipun begitu seorang calon guru juga perlu memiliki pengetahuan tentang PCK (Kaya, 2009; Nillson and Loughran, 2012). Penelitian lain mengungkapkan bahwa, seorang guru akan memiliki kemampuan PCK yang baik jika PCK dikembangkan sejak mereka jadi calon guru (Nurmatin \& Purwianingsih, 2017). Oleh karena itu, PCK sebagai pengetahuan dasar tidak hanya diperlukan oleh guru senior dan guru pemula tetapi PCK juga diperlukan oleh calon guru agar pada saat menjadi guru tidak hanya sekedar menyampaikan materi pelajaran kepada peserta didik, tetapi juga memikirkan dengan baik bagaimana agar peserta didik dapat memahami konsep materi dengan mudah. Jika seorang calon guru menginginkan konsep materi yang disampaikan dapat diterima dengan mudah oleh peserta didik maka calon guru harus menciptakan pembelajaran sebagai lingkungan sendiri (Nilsson and Lougharn, 2012). Dengan demikian, berdasarkan alasan-alasan tentang pentingnya kemampuan PCK dimiliki oleh calon guru dalam rangka menghadapi pendidikan abad 21, maka dirasa perlu dilakukan penelitian menganalisis kemampuan PCK calon guru dalam menghadapi pendidikan abad 21.

\section{METODE}

Salah satu sekolah tinggi berbasis agama islam di Tasikmalaya dijadikan sebagai tempat penelitian. Mahasiswa yang dijadikan sebagai subjek merupakan enam mahasiswa tingkat 2 yang mengikuti perkuliahan pendidikan IPA. Selanjutnya, subjek penelitian dalam penelitian ini dinamakan sebagai partisipan. Metode penelitian yang digunakan adalah kualitatif yakni penelitian tanpa memberikan treatment dalam pelaksanaannya (Cresswel, 2012). Metode penelitian kualitatif digunakan dalam penelitian ini guna memaparkan kemampuan partisipan dalam melaksanakan pembelajaran melalui 
simulasi pembelajaran saat perkuliahan berlangsung. Sebelum pengambilan data, dilakukan terlebih dahulu telaah kurikulum untuk mengetahui kurikulum yang digunakan di sekolah tingkat dasar saat ini. Setelah telaah kurikulum, peneliti ikut serta dalam kegiatan simulasi mengajar partisipan untuk mengobservasi kemampuan PCK partisipan dalam melaksanakan pembelajaran.

\section{HASIL DAN PEMBAHASAN}

Karakteristik pendidikan abad 21 yang menekankan pada kemampuan siswa untuk berpikir kritis, mampu menghubungkan ilmu dengan dunia nyata, menguasai teknologi informasi komunikasi, dan berkolaborasi sesuai dengan pilar pendidikan yang diungkapkan oleh UNESCO. Pilar pendidikan menurut UNESCO yakni Learning To Know, Learning to Do, dan Learning to Live Together. Oleh karena itu, peneliti mengobservasi kemampuan PCK partisipan berdasarkan pilar pendidikan yang dikemukakan oleh UNESCO. Kemampuan PCK partisipan dalam melaksanakan pembelajaran IPA dalam rangka menuju pendidikan Abad 21 ditunjukkan dalam Tabel 1.1.

Tabel 1. Hasil Observasi

\begin{tabular}{|c|c|c|c|}
\hline \multirow{2}{*}{ Partisipan } & \multicolumn{3}{|c|}{ Kegiatan pembelajaran } \\
\hline & Learning To Know & Learning to Do & Learning to Live Together \\
\hline $\mathrm{EC}$ & $\begin{array}{l}\text { Media pembelajaran yang digunakan } \\
\text { berupa video. Namun video yang } \\
\text { dimunculkan tidak memunculkan konflik } \\
\text { kognitif. Video yang dimunculkan lebih } \\
\text { cocok digunakan untuk belajar secara } \\
\text { mandiri. Kegiatan pembelajaran lebih } \\
\text { didominasi oleh guru. }\end{array}$ & $\begin{array}{l}\text { Tidak terdapat } \\
\text { percobaan }\end{array}$ & $\begin{array}{l}\text { Pembelajaran dilakukan } \\
\text { dengan metode ceramah. }\end{array}$ \\
\hline FA & $\begin{array}{l}\text { Pembelajaran diawali dengan pertanyaan } \\
\text { yang berupa konsep. Tidak ada media } \\
\text { yang digunakan untuk memunculkan } \\
\text { konflik kognitif pada siswa. Konsep } \\
\text { materi yang disampaikan masih terdapat } \\
\text { kesalahan. }\end{array}$ & $\begin{array}{l}\text { Melakukan } \\
\text { percobaan dengan } \\
\text { membuat kincir } \\
\text { angin dari kertas } \\
\text { tetapi di akhir } \\
\text { pembelajaran }\end{array}$ & $\begin{array}{l}\text { Pembelajaran dilakukan } \\
\text { dengan guru sebagai pusat } \\
\text { informasi, tidak muncul } \\
\text { pembelajaran secara } \\
\text { berkelompok atau diskusi } \\
\text { dalam kelas }\end{array}$ \\
\hline EG & $\begin{array}{l}\text { Pembelajaran dilakukan dengan cara } \\
\text { ceramah. Tidak terdapat media } \\
\text { pembelajaran yang digunakan. }\end{array}$ & $\begin{array}{l}\text { Tidak terdapat } \\
\text { percobaan dalam } \\
\text { pembelajaran. }\end{array}$ & $\begin{array}{l}\text { Pembelajaran dilakukan } \\
\text { dengan guru sebagai pusat } \\
\text { informasi, tidak muncul } \\
\text { pembelajaran secara } \\
\text { berkelompok atau diskusi } \\
\text { dalam kelas }\end{array}$ \\
\hline RI & $\begin{array}{l}\text { Muncul sedikit konflik kognitif melalui } \\
\text { contoh-contoh energy dalam kehidupan } \\
\text { sehari-hari.Partisipan memberikan materi } \\
\text { dengan ceramah. Setelah ceramah ada } \\
\text { media berupa booklet kecil yang meminta } \\
\text { siswa untuk diisi dengan benda-benda yang } \\
\text { menghasilkan energi }\end{array}$ & $\begin{array}{l}\text { Terdapat } \\
\text { pengamatan } \\
\text { melalui gambar- } \\
\text { gambar yang } \\
\text { berkaitan dengan } \\
\text { materi namun } \\
\text { disimpan diakhir } \\
\text { pembelajaran }\end{array}$ & $\begin{array}{l}\text { Belajar secara tradisional } \\
\text { yakni dengan metode } \\
\text { ceramah }\end{array}$ \\
\hline RK & $\begin{array}{l}\text { Pembelajaran dilakukan dengan ceramah. } \\
\text { Muncul sedikit konflik kognitif terkait } \\
\text { dengan manfaat energy yang dihubungkan } \\
\text { dengan kekuatan energy dari makanan. } \\
\text { Media yang digunakan adalah peralatan } \\
\text { yang ada di ruang kelas seperti lampu, } \\
\text { infokus, suara guru sebagai contoh dari } \\
\text { energy. }\end{array}$ & $\begin{array}{l}\text { Terdapat kegiatan } \\
\text { pengamatan melalui } \\
\text { gambar tapi di akhir } \\
\text { pembelajaran }\end{array}$ & $\begin{array}{l}\text { Pembelajaran dilakukan } \\
\text { dengan metode ceramah }\end{array}$ \\
\hline NA & $\begin{array}{l}\text { Partisipan menampilkan gambar terkait } \\
\text { dengan perubahan energy sebagai bahan } \\
\text { pengamatan pertama. Pengamatan kedua }\end{array}$ & $\begin{array}{l}\text { Percobaan dilakukan } \\
\text { secara demonstrasi. } \\
\text { Percobaan yang }\end{array}$ & $\begin{array}{l}\text { Belajar secara berkelompok } \\
\text { yang kemudian perwakilan } \\
\text { kelompok diminta untuk }\end{array}$ \\
\hline
\end{tabular}




\begin{tabular}{|c|c|c|c|}
\hline \multirow{2}{*}{ Partisipan } & \multicolumn{3}{|c|}{ Kegiatan pembelajaran } \\
\hline & Learning To Know & Learning to Do & Learning to Live Together \\
\hline & $\begin{array}{l}\text { menampilkan perubahan energy panas } \\
\text { menjadi energi gerak dengan menggunakan } \\
\text { kertas yang dibentuk spiral disimpan di atas } \\
\text { lilin yang menyala sehingga kertas berputar. } \\
\text { Dengan percobaan tersebut siswa } \\
\text { mengamati kemudian menganalisis } \\
\text { mengapa kertas spiral yang diletakan di atas } \\
\text { api yang menyala bisa berputar. Partisipan } \\
\text { terampil dalam menggunakan gambar dan } \\
\text { percobaan sebagai bahan pengamatan } \\
\text { sehingga memunculkan konflik kognitif } \\
\text { pada siswa yang menimbulkan hipotesis } \\
\text { dari siswa }\end{array}$ & $\begin{array}{l}\text { dilakukan adalah } \\
\text { percobaan untuk } \\
\text { membuktikan } \\
\text { adanya perubahan } \\
\text { energi panas } \\
\text { menjadi energi } \\
\text { gerak. }\end{array}$ & $\begin{array}{l}\text { mengungkapkan pendapat } \\
\text { terkait dengan hasil diskusi } \\
\text { kelompoknya tentang } \\
\text { perubahan energi }\end{array}$ \\
\hline
\end{tabular}

Tabel 1 menunjukkan bahwa kemampuan PCK partisipan sudah mulai terlihat, namun belum secara maksimal dalam konteks pendidikan abad 21. Hal ini ditunjukkan dengan lima dari enam orang partisipan masih melaksanakan pembelajaran dengan menggunakan metode ceramah. Satu dari lima orang partisipan yang menggunakan metode ceramah yakni FA membuat sebuah kegiatan pembelajaran dengan melakukan percobaan. Namun, percobaan disimpan diakhir pembelajaran sehingga percobaan yang dilakukan hanya sebatas membuktikan konsep IPA yang sudah partisipan jelaskan dalam metode ceramah. Sementara itu, dua dari lima orang partisipan yang melaksanakan pembelajaran dengan cara ceramah yakni RI, dan RK membuat kegiatan yang mengajak peserta didik berpikir yang seharusnya digunakan untuk mengkontruksi konsep IPA pada peserta didik. Namun RI dan RK menempatkan kegiatan tersebut diakhir pembelajaran sehingga proses berpikir tersebut hanya digunakan sebagai proses pengulangan materi. Dengan demikian kemampuan PCK partisipan sudah mulai terlihat tetapi belum maksimal. Ini dikarenakan partisipan belum memiliki pengalaman yang banyak dalam melaksanakan pembelajaran. Kemampuan PCK akan meningkat seiring dengan pengalaman pelaksanaan pembelajaran di kelas. Sesuai dengan ungkapan Loughran, et al. (2012) bahwa PCK merupakan pengetahuan guru yang berkembang dari waktu ke waktu melalui pengalaman, tentang bagaimana cara mengajarkan sebuah konten pada konsep tertentu dengan cara tertentu agar memunculkan pemahaman pada peserta didik.

Metode ceramah yang digunakan lima partisipan berdampak pada kegiatan learning to know pada pembelajaran konsep IPA. Peserta didik seharusnya mendapatkan pengetahuan sebanyak-banyaknya melalui pengalaman tidak muncul secara maksimal. Dengan tidak maksimalnya learning to know pada pembelajaran maka berdampak pada dua pilar lainnya yakni learning to do dan learning to live together. Learning to do yang mengajak peserta didik untuk ikut serta dalam memecahkan permasalahan konsep IPA melalui sebuah tindakan nyata seperti percobaan tidak ada. Dengan tidak adanya percobaan atau pengamatan yang bertujuan untuk mengkontruksi pengetahuan konsep IPA dalam pembelajaran maka kemampuan berpikir kritis pada peserta didik yang diharapkan dalam pembelajaran tidak muncul. Learning to live together dalam pembelajaran salah satunya dimunculkan dalam bentuk pembelajaran secara berkelompok agar peserta didik sadar bahwa mereka adalah bagian dari kelompok. Dengan demikian, pembelajaran yang dilakukan dengan metode ceramah dimana guru sebagai pusat informasi dan peserta didik sebagai penerima informasi tidak terjadi interaksi antar individu peserta didik. Dengan tidak maksimalnya learning to know yang berdampak pada learning to do dan learning to live together dalam proses pembelajaran menunjukkan bahwa kemampuan PCK partisipan dalam menghadapi pendidikan abad 21 belum maksimal karena belum mampu menumbuhkan berpikir kritis pada peserta didik saat pembelajaran berlangsung. Sementara karakteristik dalam pendidikan abad 21 menekankan pada kemampuan siswa untuk berpikir kritis, mampu menghubungkan ilmu dengan dunia nyata, menguasai teknologi informasi komunikasi, dan berkolaborasi (Janah dkk, 2019). 


\section{SIMPULAN}

Kemampuan PCK calon guru partisipan sudah mulai terlihat namun belum secara maksimal dalam menghadapi pendidikan abad 21. Calon guru partispan melaksanakan pembelajaran secara ceramah, hanya ada satu partisipan yang melaksanakan pembelajaran dengan melakukan percobaan. Pembelajaran dengan ceramah tidak memunculkan learning to know, learning to do dan learning to live together sebagai pilar pendidikan yang sesuai dengan karakteristik pendidikan abad 21 .

\section{REFERENSI}

Anggoro, S. Harmianto, S \& Yuwono,P.D. (2018). Upaya Meningkatkan Kemampuan Pedagogik Guru Melalui Pelatihan Pembelajaran Tematik Sains Menggunakan Inquiry Learning Process Dan Science Activity Based Daily Life, Jurnal Pengabdian dan Pemberdayaan Masyarakat, ISSN: 2549-8347 (Online), ISNN: 2579-9126 (Print) Volume 2 No. 1 Maret 2018

Brown, P., Friedrichsen, P., \& Abell, S. (2013). The Development of Prospective Secondary Biology Teachers PCK. Journal of Science Teacher Education, 24(1), 133-155.

Cresswel, J.W. (2012). Educational Research: Planing, Conducting, and Evaluating Quantitative and Research. Boston: Research

Etkina, E. (2010). Pedagogical Content Knowledge and Preparation of High School Physics Teachers. Physical Review Special Topics - Physics Education Research 6, 020110 (2010)

Hanuscin, D. L. (2013). Critical Incidents in the Development of Pedagogical Content Knowledge for Teaching the Nature of Science: A Prospective Elementary Teacher's Journey. Journal of Science Teacher Education, 24(6), 933-956.

Hume, A., \& Berry, A. (2011). Constructing CoRes-a Strategy for Building PCK in Pre-service Science Teacher Education. Research in Science Education, 41(3), 341-355. Iserbyt, P., Ward, P., \& Li, W. (2017). Effects of improved content knowledge on pedagogical content knowledge and student performance in physical education. Physical Education and Sport Pedagogy, 22(1), 7188.

Janah, S. R., Suyitno, H. \& Rosyida, I. (2019). Pentingnya Literasi Matematika dan Berpikir Kritis Matematis dalam Menghadapi Abad ke-2, PRISMA (Proseding Seminar Nasional Matematika) 2 (2019): 905-910 ISSN 2613-9189. [online] https://journal.unnes.ac.id/sju/index.php/prisma/

Kang, M., Kim, M., Kim, B., \& You, H. (2012.). Developing an Instrumen to Measure 21st Century Skills for Elementary Student.

Kaya, O. N. (2008). The nature of relationships among the components of pedagogical content knowledge of preservice science teachers: "ozone layer depletion" as an example. International Journal of Science Education, 30(1), 1-28. 46

Lets Talk Science. (2014). Why is science literacy so important? [online] http://www.letstalkscience.ca/about-us/why-science

Limba, A. (2014). Model Penyiapan Pedagogical Content Knowledge (PCK) Calon Guru untuk Meningkatkan Kemampuan Merancang dan Mengimplementasikan Pengajaran Fisika. Disertasi Doktor. UPI Bandung: Sekolah Pasca Sarjana

Magnusson, S., \& Krajcik, J. S. (1993). Teacher Knowledge And Representation Of Content In Instruction About Heat Energy And Temperature. National Asociation for Research in Science Teaching

Masykuri, M. (2013). Dinamika Muatan Sains dalam Pembelajaran Sekolah Dasar Pada Kurikulum 2013. Makalah Pendamping Seminar Nasional Kimia dan Pendidikan Kimia V. [online] http://snkpk.fkip.uns.ac.id/wp-content/uploads/2016/07/A-09 DINAMIKA-MUATAN-SAINSDALAM-PEMBELAJARAN-SEKOLAH-DASAR-PADA-KURIKULUM-2013_MohammadMasykuri.pdf 
Nilsson, P., \& Loughran, J. (2012). Exploring the Development of Pre-Service Science Elementary Teachers' Pedagogical Content Knowledge. Journal of Science Teacher Education, 23(7), 699721.

Nurmatin, S \& Purwianingsih, W. (2017). Capturing The Pck Ability Of Prospective Science Teachers Using CoRe And PaP-er. Indonesian Journal of Science Education, Vol 6 (2) 2017, 271-276, DOI: 10.15294/jpii.v6i2.9507

Menteri Pendidikan Nasional. (2007). Peraturan Menteri Pendidikan Nasional Republik Indonesia Nomor 16 Tahun 2007 tentang Standar Kualifikasi Akademik dan Kompetisi Guru. Jakarta: Departemen Pendidikan

Mubarak, A. Z. (2018). Pendidikan Di Era Revolusi Industri 4.0 Dan Problematika Pendidikan Tinggi. Yogyakarta: Gending Pustaka

Peraturan Pemerintah No. 19 Tahun 2005 Tentang Standar Nasional Pendidikan

Rustaman, N.Y. \& Widodo. A. (2013). Profile Of Prospective Science Teachers' Pedagogical Content Knowledgeas Documented From Videotapes And Thesis. Indonesia University of Education.

Rozenszajn, R., \& Yarden, A. (2014). Expansion of Biology Teachers' Pedagogical Content Knowledge (PCK) During a Long-Term Professional Development Program. Research in Science Education. 44: 189-213. DOI 10.1002/s11165-013-9378-6.

Seung, E., Bryan, L. A., \& Haugan, M. P. (2012). Examining Physics Graduate Teaching Assistants' Pedagogical Content Knowledge for Teaching a New Physics Curriculum. Journal of Science Teacher Education, 23(5), 451-479.

Shulman, L.S.(1987). Knowledge and Teaching: Foundation of The New Reform. Harvard Educational Review. 57 (1) February 1987

Sukanti, \& Sumarsih. (Tanpa Tahun). Peran Guru Bidang Studi Sebagai Pengembang Kurikulum Tingkat Satuan Pendidikan (KTSP). Tersedia http://staff.uny.ac.id. Diakses 30 Mei 2015

Sukinarti. (2014). Kendala Penerapan Pembelajaran Tematik di Kelas Rendah Sekolah Dasar. Perspektif Ilmu Pendidikan (28) 2 Oktober 2014.

Yusnawarni. (2014). Peran Bahasa Indonesia Dalam Pembelajaran Tematik Terpadu Melalui $\begin{array}{lllll}\text { Pendekatan } & \text { Saintifik. } & \text { Madah } & \text { (5) } & 2 .\end{array}$ http://ejurnalbalaibahasa.id/index.php/madah/article/view/509/290 